\title{
Architectural Contextualization of Heritage Museum Artifacts Using Augmented Reality
}

\author{
ESLAM NOFAL, KU Leuven, Belgium and Assiut University, Egypt \\ AHMED ELHANAFI, German University in Cairo, Egypt \\ HENDRIK HAMEEUW, Royal Museums of Art and History, and KU Leuven, Belgium \\ ANDREW VANDE MOERE, KU Leuven, Belgium
}

\begin{abstract}
Context is crucial for understanding meanings and values of heritage. Heritage artifacts from recently destroyed monuments are exhibited in various museums around the world; contextualizing those isolated heritage artifacts enables museums to communicate the architectural and spatial qualities of the original context to their visitors. With the rapid evolution of digital technologies, museums started to incorporate Augmented Reality (AR), to present and interpret their collections in more appealing and exciting ways. AR not only enriches heritage communication, but also encourages interactivity for visitors in museums. Through a field study in a real-world museum environment, we investigated how AR enhances the communication of the original context of an isolated artifact from the Nimrud palace in Iraq. We deployed a mixed-methods evaluation methodology that led to an effective and engaging communication of the architectural context of that artifact, particularly perceiving and recalling architectural features and spatial dimensions. We conclude the paper with a set of discussion points about how AR positively affects visitors' memorability of architectural qualities, and how it provokes their curiosity to explore more information. We highlight some considerations about AR visualization, such as how levels of embellishment direct the user's focus of attention, and which aspects should be considered when using AR abstract visualization to communicate heritage. We outline several design recommendations to overcome current AR usability issues in museums concerning intuition, freedom of movement, and age-related differences.
\end{abstract}

\section{Key words:}

Augmented reality, cultural heritage, communication, architectural context, museum artifacts.

SDH Reference:

Eslam Nofal et al. 2018. Architectural contextualization of heritage museum artifacts using augmented reality. SDH, 2, 1, 42-67.

DOI : $10.14434 / \mathrm{sdh} . \mathrm{v} 2 \mathrm{i} 1.24500$

This work is supported by a PhD scholarship funded by the Egyptian Ministry of Higher Education.

Author's address: Eslam Nofal, Research[x]Design, Department of Architecture, KU Leuven, Kasteelpark Arenberg 1 - bus 2431 , 3001 Leuven, Belgium; email: eslam.nofal@kuleuven.be \& Department of Architecture, Faculty of Engineering, Assiut University, 71516 Assiut, Egypt; email: esnofal@yahoo.com; Ahmed Elhanafi, Media Engineering and Technology Faculty, German University in Cairo, Cairo, Egypt; email: ahmed.elhanafy95@gmail.com; Hendrik Hameeuw, Antiquity Department, Royal Museums of Art and History, Jubelpark 10, B-1000 Brussels, Belgium; email: h.hameeuw@kmkg-mrah.be \& Research Unit Ancient History, KU Leuven, Blijde-Inkomststraat 21, 3000 Leuven, Belgium; email: hendrik.hameeuw@kuleuven.be; Andrew Vande Moere, Research[x]Design, Department of Architecture, KU Leuven, Kasteelpark Arenberg 1 - bus 2431,3001 Leuven, Belgium; email: andrew.vandemoere@kuleuven.be

(C) [2018] by the author; licensee Studies in Digital Heritage, IU, Bloomington (IN), USA. This article is an open access article distributed under the terms and conditions of the Creative Commons Attribution License (CC BY-NC). 


\section{INTRODUCTION}

Context can be described as an environment or a background that combines various elements or items to create a whole. All types of knowledge are context-related [Nesbitt 1996], as the context is the key to understand any associated knowledge. In architectural heritage, like many other fields, context plays an important role in communicating different meanings and values. Outstanding values of architectural heritage might be attributed to architectural qualities, structural aspects, and the historical or social significance of monuments and archeological sites.

In museums, visitors are interested in learning about the origin and time period of artifacts. An artifact of importance to heritage may have little or no intrinsic value when it is decontextualized in a museum, as its value arises from the original context [Thompson, 2007]. This context is usually connected to a specific environment that consists of a particular space and time period. There are three core aspects related to the context of heritage. First, architectural context, such as how the artifact was an element of design style or decoration of a particular interior space. Second, historical context, such as how the artifact is attached to an important event or a historic figure. And finally, social context, such as how the qualities of the artifact become a focus of spiritual, political, symbolic or other sentiment to a group of people.

It is believed that displacing heritage artifacts from the original location where they were found means that a great deal of contextual information is lost [Thompson 2007]. This might imply that it could be ideal to keep heritage artifacts in their original context for more effective communication and interpretation of these artifacts. However, the case is different when the original context of the artifacts is heritage in danger. As such, isolated artifacts exhibited in remote museums are considered to be of enormous inherent significance for their absolute value and quality. Yet the value of their architectural qualities and historical significance cannot be communicated unless they are contextualized in some way or form.

In particular, our research focuses on communicating the architectural context of heritage museum artifacts. We are exceptionally motivated by the recent major damage to many cultural heritage sites in Syria and Iraq, such as those in the cities of Palmyra and Nimrud [Cerra et al. 2016]. Several artifacts (i.e. fragments) from these sites are scattered around the world in different museums. These artifacts are considered as silent witnesses of the value and importance of the recently destroyed monuments. Accordingly, we aim to architecturally contextualize such museum artifacts using digital technologies to raise community awareness and to enable visitors to appreciate the cultural heritage in more experiential ways.

During the past two decades, several emerging digital technologies have already profoundly influenced the way of disseminating and communicating cultural heritage to lay visitors [King and Stark 2016]. Immersive technologies such as virtual and augmented reality create an effective communication with cultural heritage, offering meaningful relationships between heritage artifacts, visitors and context [Reffat and Nofal 2013]. Augmented Reality (AR) technology allows for superimposed information on virtual objects, as if they coexist in the real world [Azuma et al. 2001].

As such, it enables heritage professionals and museum curators to visualize heritage artifacts and to enhance museum visiting experiences [Mohammed-Amin 2015; Nofal 2013]. With the rapid evolution of AR technology, museums incorporated AR to present and interpret their collections in more 


\section{2:44 E. Nofal, et al.}

appealing and exciting ways. AR applications provide meaningful insights and wide-range interpretation of heritage museum artifacts [Damala et al. 2007]. In contrast to virtual reality, AR enables an alternative way of interaction between museum visitors and artifacts by breaking the barrier between virtual objects and the physical museum artifacts [Li et al. 2012]. For instance, AR facilitates visualizing and interacting with 3D digitized museum collections [Mourkoussis et al. 2002; Wojciechowski et al. 2004], enabling visitors to look at artifacts from different points of view. Further, AR enriches the museum visit by revealing the hidden details of museum artifacts, such as geometry and color [Ridel et al. 2014], or even by supporting virtual restoration of partially damaged artifacts [Stanco et al. 2012]. AR has been also used to geo-tag contextual information for guiding and orienting museum visitors [Mohammed-Amin 2015]. Some museums use AR applications for increasing social interaction among visitors by allowing them to share personalized tags for museum artifacts while exploring the exhibit [Cosley et al. 2009]. Moreover, AR is used for educational purposes in museums in order not only to promote participation and motivation, but also to create an informal and novel learning environment by coupling the virtual space and the physical scenes [Chang et al. 2014; Yilmaz, 2016]. Thus, visitors comprehend the profound meaning embedded in the exhibits through observation, interpretation, and evaluation of the physical artifacts during their visit. Finally, several museums use interactive AR applications as a catalyst for attracting children and young visitors [Jakobsen et al. 2018], incorporating pervasive game strategies to enhance historical content interpretation as well as user engagement [Angelopoulou et al. 2012].

Consequently, we hypothesize that AR is capable of contextualizing heritage museum artifacts and of increasing the engagement and memorability of museum visitors. Through a field study in a realworld museum environment, we deployed a mixed-methods evaluation methodology to investigate how AR enhances the communication of the architectural context of an isolated artifact. We chose a relief from the Nimrud palace in Iraq, exhibited at the Royal Museums of Art and History in Brussels, because it is considered to be an exceptional museum artifact due to the recent deliberate destruction of its original context.

\section{ASSYRIAN RELIEF OF A WINGED GENIUS HEAD FROM NIMRUD PALACE}

One of the key masterpieces of the Ancient Near Eastern Collections of the Royal Museums of Art and History (RMAH) in Brussels consists of a very well carved relief depicting the head of a genius crowned with three deifying horns, an elaborate beard and headdress, and some remnants of wings (0.1934), shown in Fig. 1a. In the exhibition room it is displayed together with a set of other reliefs and artifacts, all originating from ancient Mesopotamia (Fig. 1b). Museum visitors are surely astonished by the artistic quality of such $9^{\text {th }}-8^{\text {th }}$ century BCE relics, but they might not be aware of their historic value, not to mention the architectural context where they were once installed.

In the spring of 1847, the British adventurer and self-taught archaeologist Austen Henri Layard excavated (at the site of Nimrud/Kalhu in present-day Iraq) what he labelled 'Room $S$ ' of the Northwest palace of the Assyrian king Assurnasirpal II. What he found and described in his excavation reports were many more than life-size reliefs, depicting all sorts of deities, sacred trees, guards (or eunuchs) and the king himself. What he had discovered was one of the grand roofed halls of the palace, which was made of mudbrick and adobe. The large stone slabs - orthostats - flanked

Studies in Digital Heritage, Vol. 2, No. 1, Publication date: September 2018 
and supported the rough walls all around the interior. They were decorated with reliefs that were originally painted and carved by the best craftsmen of the empire. The entire set-up was designed to impress the king's subjects and foreign visitors. The entire Northwest palace counted dozens of such rooms and halls; it made the complex one of the finest and most impressive architectural wonders of its era.

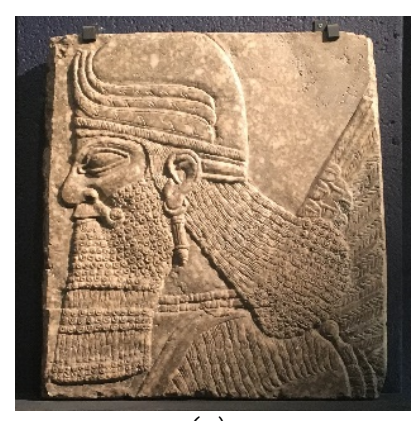

(a)

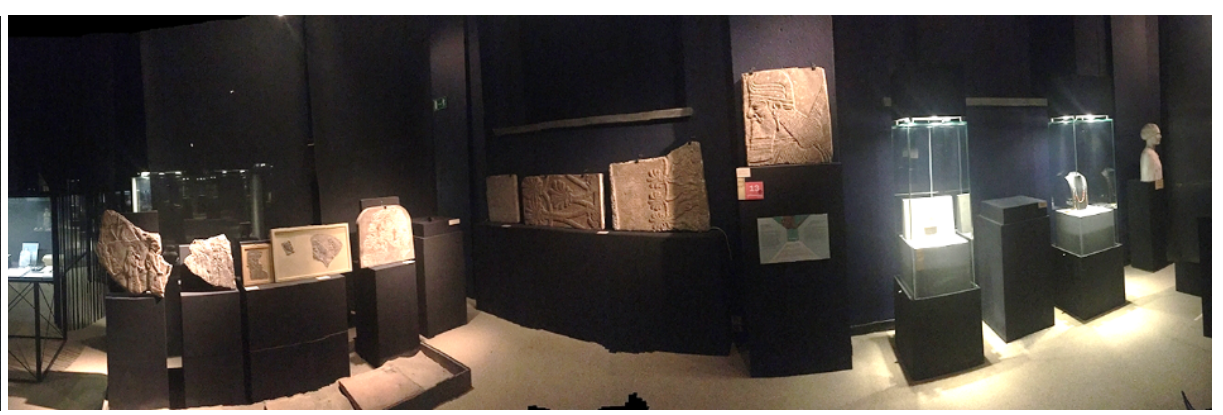

(b)

Figure 1. The artifact: Assyrian relief of winged genius head from the Nimrud palace; (a) the relief exhibited at $R M A H$, and (b) a panoramic view of the exhibited relief among other ancient Near Eastern collections.

Layard shipped a few of these reliefs he found in Room S to the British Museum [Layard 1849, Part II, 7]. However, he did not mention that he had also been cutting out the heads of some of these relief figures. That was revealed beyond doubt in the 1970s, when Iraqi archaeologists re-excavated Room $S$ and discovered several mutilated slabs with winged deities. Regarding the aforementioned masterpiece of the RMAH, historical research has revealed that the head cut from slab 28 of Room S was probably given to the English Captain John Hope by Layard as a gift, eventually to end up in the RMAH in 1934 [Englund 2003]. At Nimrud, the remaining slabs were re-erected in their original positions during the intensive restoration work carried out in the 1980-90s by the Iraqi Ministry of Culture. Unfortunately, when large parts of the Northwest palace were digitally restored in a 3D model [Paley 2002], Room S was not included. The main reason for that omission was that the majority of the original slabs were still in situ at Nimrud; only a few large pieces and a number of small fragments, such as 0.1934 of the RAMH, were scattered around the world in multiple collections, making it more difficult to obtain accurate and complete data to incorporate the room into that 3D model. This reality ended in a disaster in March 2015; the not-digitally-preserved-and-restored Room $S$ became the focal point of the deliberate destruction of cultural heritage by militants of ISIL. In dramatic video footage, slab 28 of Room S is being mutilated with a sledgehammer (Fig. 2). Ultimately, the extremists would dynamite the entire palace, leaving everything behind in complete rubble and ruins.

The RMAH artifact (Fig. 1a) is now the last silent witness of slab 28, an architectural decorative detail once part of a magnificent grand palace hall. Exploring and finding methods to contextualize such an exceptional museum artifact must be determined as a mission. 


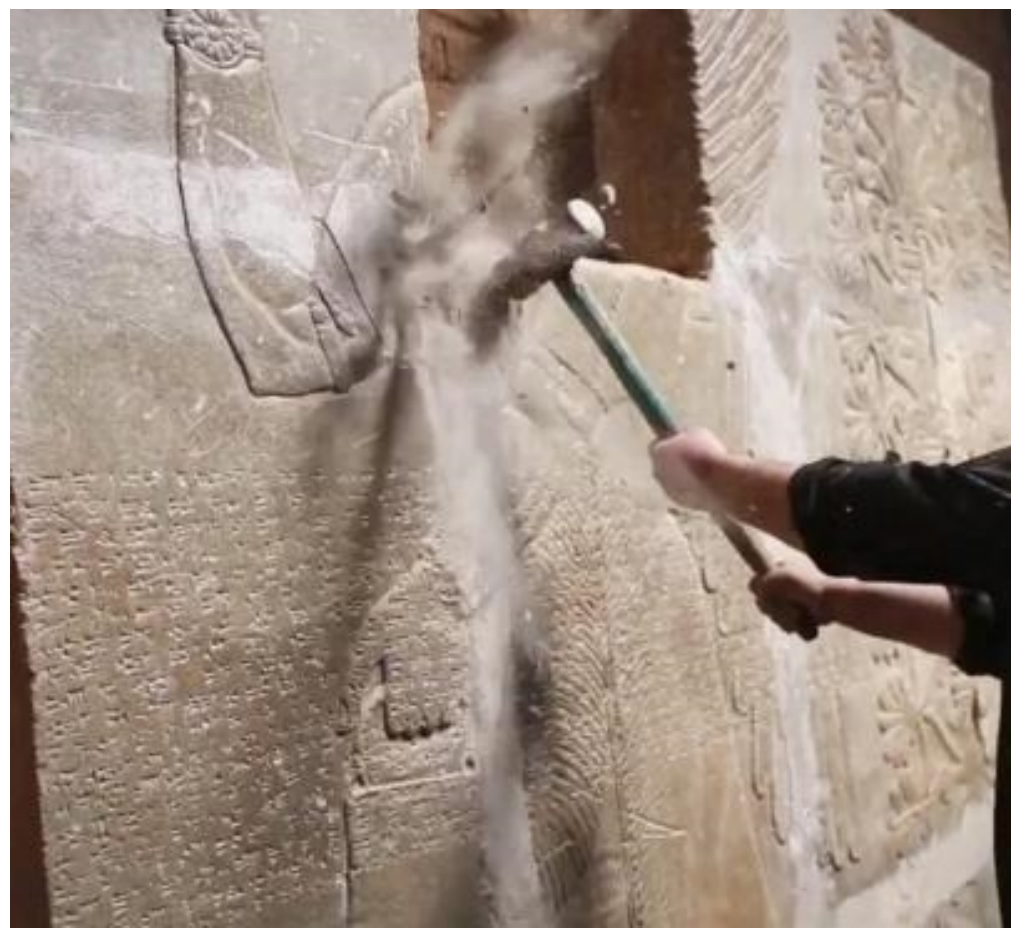

Figure 2. Deliberate destruction of slab 28 in Room S of the Northwest Palace in Nimrud, Iraq (March 2015) ${ }^{1}$. Note the cut-out piece, i.e. the deliberate removal of the head by Austen Henry Layard (most probably in 1847 or 1850).

\section{METHODOLOGY}

In order to architecturally contextualize the RMAH's artifact from Nimrud palace, we designed and developed an AR application, followed by a mixed-methods evaluation study with 46 museum visitors. In particular, we explored the following questions: (a) how the utilization of AR influences the communication of the architectural and spatial context of museum artifacts, and (b) how AR affects user engagement in a museum environment.

\subsection{Designing and developing the AR application}

The collected information about Room S varied in its certainty. From authentic references (i.e. the Nimrud book published by the British School of Archaeology in Iraq [Oates and Oates 2001], and the "Northwest Palace at Nimrud" portal on the Cuneiform Digital Library Initiative website [CDLI 2018]), we were certain about its location in the palace and its floor plan with the distribution of panels/slabs along the internal walls (Fig. 3). Other information, such as the height of the room, its different openings, the ceiling structure and the friezes on the walls, was insufficient.

\footnotetext{
${ }^{1}$ Video emerged in social media purportedly showing ISIL fighters militants bulldozing the ancient Assyrian city of Nimrud (source: Chanel 4 News on YouTube: https://www.youtube.com/watch?v=wGiY7ZDKZSE on April 12, 2015)
} 


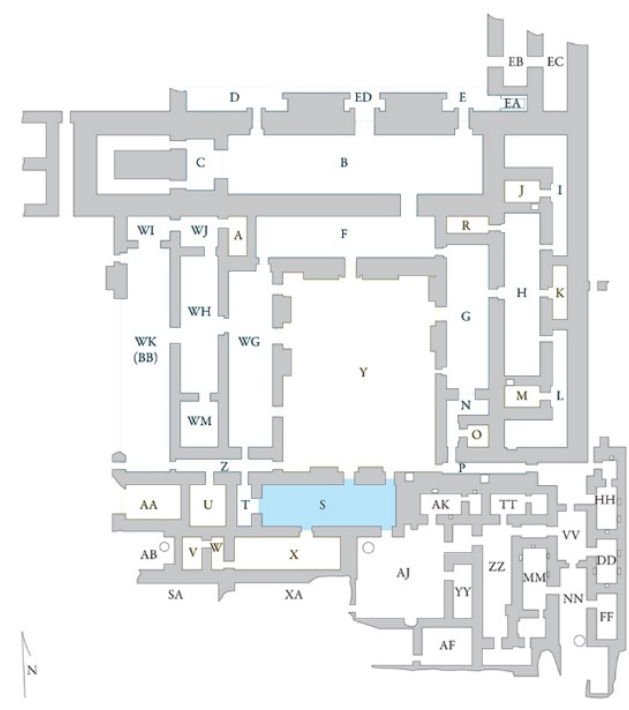

(a)

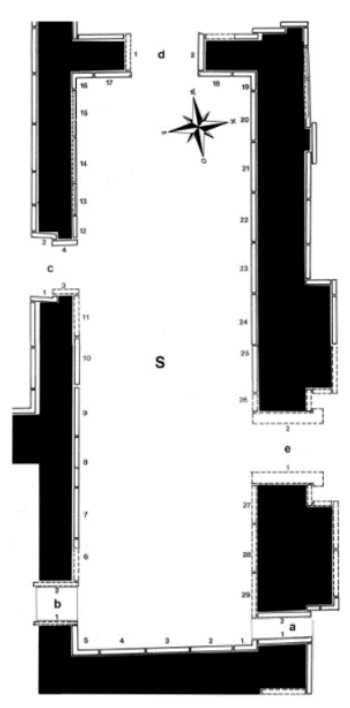

(b)

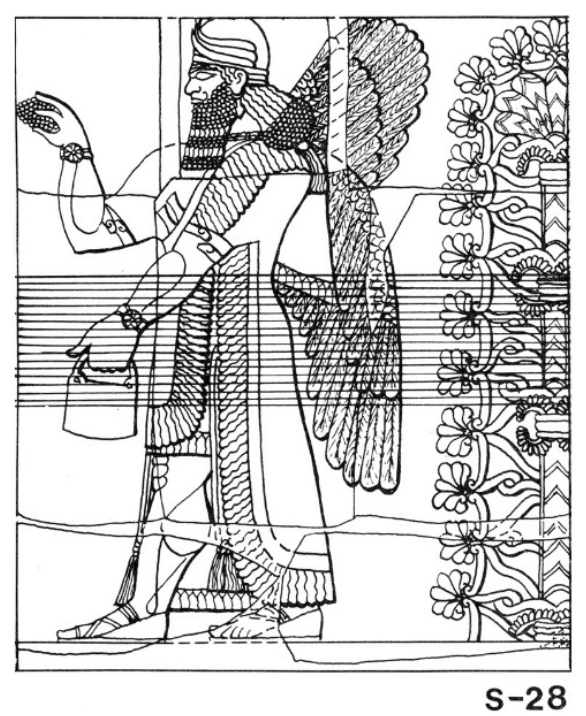

(c)

Figure 3. Collected information from historical references about the original context [CDLI 2018]: (a) floor plan of the Nimrud Northwestern Palace, (b) floor plan of Room S, where the artifact was located, and (c) the complete drawing of the slab (S-28) showing the location of the artifact on the slab.

Due to this uncertainty, we estimated the missing spatial and architectural qualities based on the information acquired from other rooms in the palace. These architectural reconstructions were based on the excavated archaeological remains and the few original artistic representations of these building complexes. None of the palace rooms and courtyards were preserved in their entirety; Room $S$ was no exception. Reconstructions are therefore based on a broad understanding of the Assyrian construction practices witnessed all over the Northwest palace. Because of these uncertainties, we decided to digitally reconstruct Room $S$ in an abstract visualization using SketchUp and Unity 3D (Fig. 4).

The abstract visualization of Room S was based on a specific design rationale. First, we intentionally designed Room S as a semi-transparent space, in order not to fully isolate visitors from the actual museum environment, while at the same time avoiding any possible risk to the priceless surrounding artifacts. Second, the salient architectural features (Fig. 4), such as the reliefs, roof beams and tiles were visualized in a cyan color to make them stand out. An abstract Assyrian pattern was used to represent the fresco friezes along the walls and the archways; these patterns had been discovered by archaeologists in the palace complex as decorations above the stone orthostats. As little of the original graphics of the frescos from Room $S$ is known for certain, the choice was made to stylize a simplified frieze inspired by similar Assyrian art. 


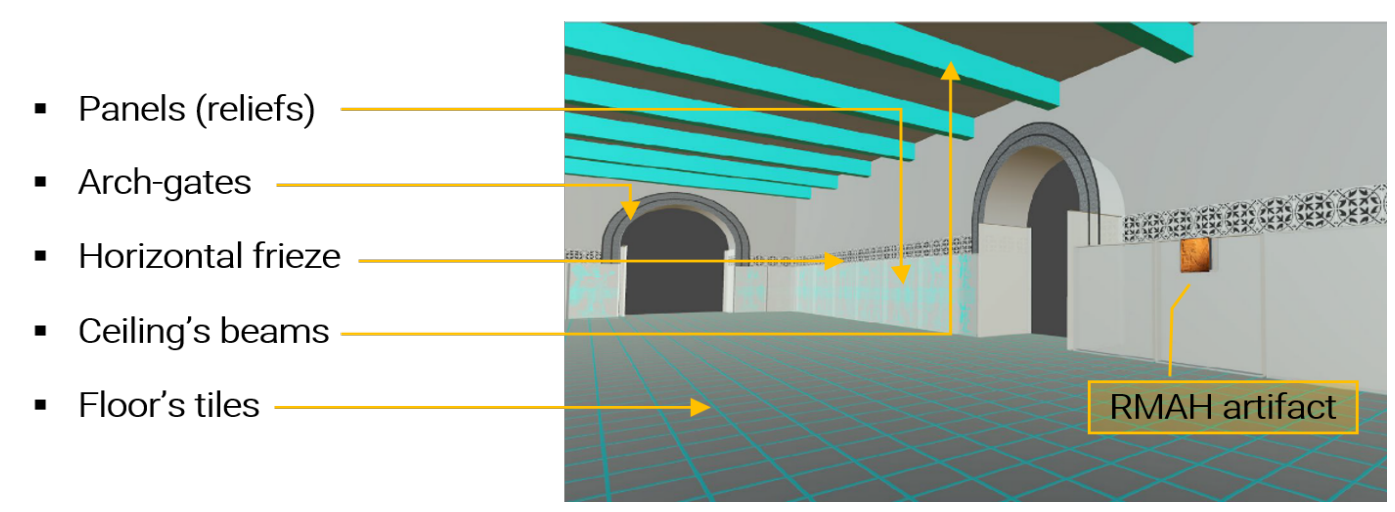

Figure 4. Digital reconstruction of Room S in an abstract visualization using SketchUp and Unity 3D, showing the original location of the RMAH artifact, and the architectural features to be displayed.

Unity 3D software was used with Vuforia SDK library to build the AR application. For tracking aspects, a 2D image marker was chosen for the development phase. A high-resolution image of the artifact was taken and uploaded to Vuforia as an image target, to be part of the Unity package generated by Vuforia. The image target was scaled and repositioned at its original place in the virtual Room S. The project was then compiled into an iOS project, imported into Xcode and run on a smartphone (i.e. iPhone 6 Plus) for testing the artifact's printed image in the lab, and then on a tablet (iPad Air 2) for evaluating the application on the actual artifact at the museum, as illustrated in Fig. 5.

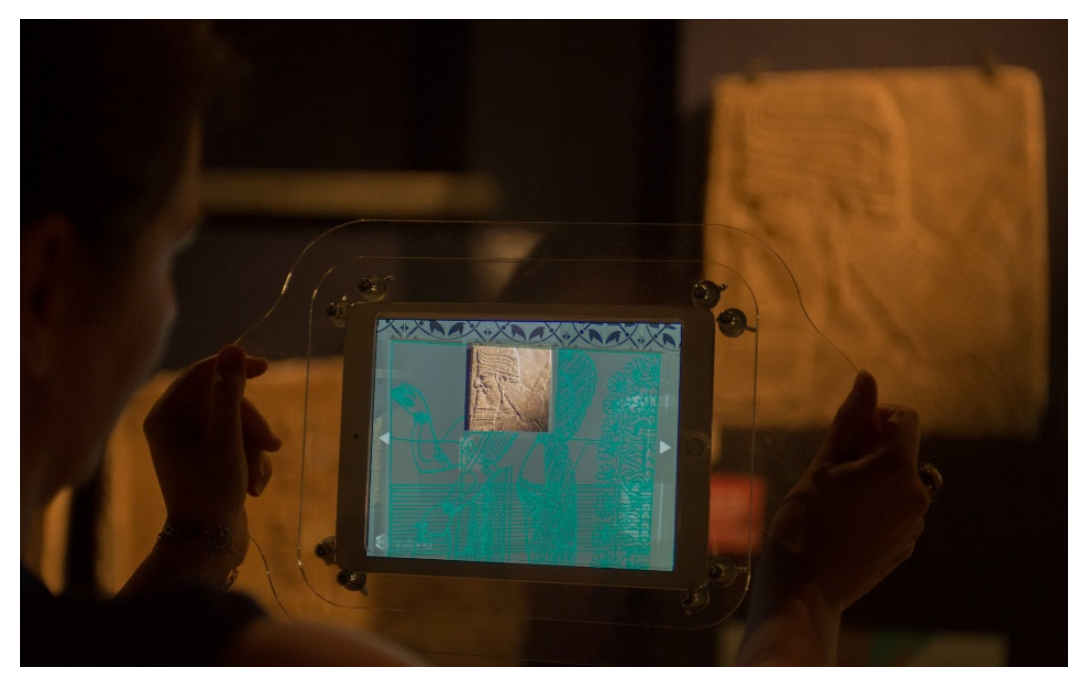

Figure 5. Contextualizing the original context of the artifact using the AR application by pointing the tablet's camera to the artifact.

Lastly, we designed and laser-cut a Plexiglas case for the iPad (Fig. 6), so that participants could hold the tablet without accidentally touching or covering up the screen with their hands. It was also intended to be a more secure and robust device for use in a museum by different groups of visitors (i.e. children, the elderly, or inexperienced people). 


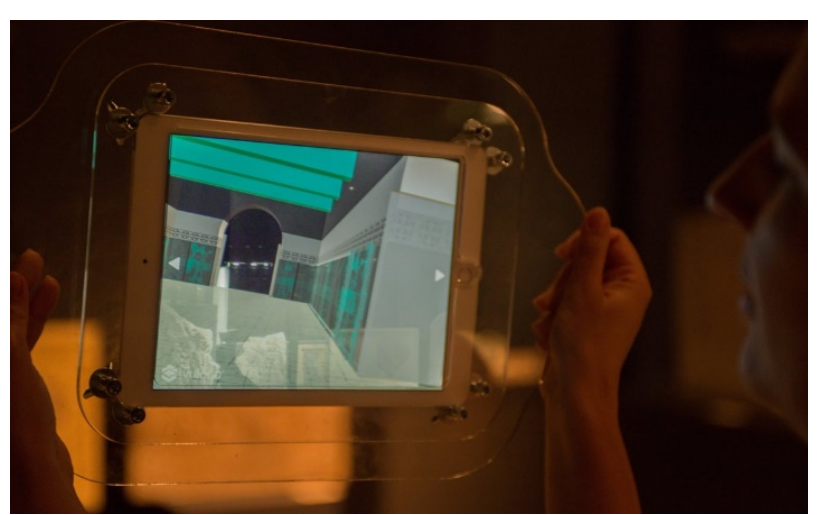

(a)

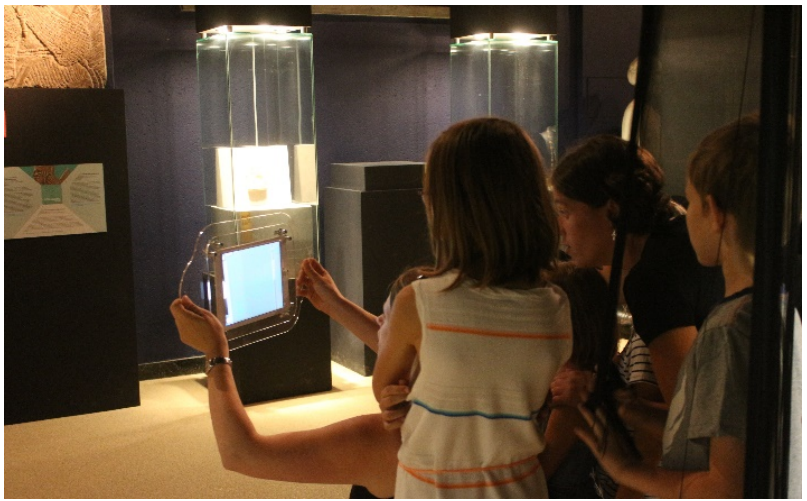

(b)

Figure 6. The custom-designed tablet case; (a) a participant using the application with the iPad inserted into the case, and (b) the case allowing a group of participants to use the application and looking at the screen.

\subsection{Evaluation methods}

The evaluation study deployed a mixed-method methodology. Museum visitors were invited first to a Conventional Visit of the artifact by looking at the relief and probably reading the labels beside it (i.e. provided by the museum in three languages: French, Dutch and English). The Conventional Visit was followed by a short interview to evaluate what they learned and whether they were able to contextualize the artifact. Subsequently, participants were invited to an AR Visiting Experience by handing them a tablet and asking them to start from a certain location (approximately two meters from the physical object) and to aim the tablet's camera towards the artifact to start interacting with the AR application. Their interaction was observed, as they were allowed to look around or to move towards the artifact. Thereafter, we invited them to partake in a semi-structured interview that was combined with a sketching task of the architectural features of Room $\mathrm{S}$, and a user experience questionnaire.

\subsubsection{Pre-task interview}

The pre-task interview, providing demographic information, aimed to evaluate what knowledge participants gained from the Conventional Visit and how they imagined the architectural context prior to their AR Visiting Experience. We asked our participants about what they learned from their visit and how they imagined the surroundings of the object (e.g., where was it located? was it a standalone artifact or was it a part of a larger entity? what did the space look like?).

\subsubsection{Observation}

During the AR Visiting Experience, all the interactions were video-recorded, observed and manually analyzed in an Excel spreadsheet. The level of user engagement was derived from the duration of their interaction, their apparent focus of attention while interacting, and their social interactions with other person(s) nearby. Furthermore, we manually noted the 'angle of view' for each participant while s/he was interacting with the AR application from the video recordings. We then graphically 
labelled the 'angle of view' in two phases: (a) as an Initial Interaction to evaluate whether and how people found the application intuitive to use, and (b) as a Guided Interaction after advising participants to look around in order to evaluate whether and how the architectural context was communicated. Their tilting angle was also noted, in order to observe whether they looked down to the floor or looked up to the ceiling. The movement of the participants, whether they moved right, left, or towards the physical object while holding the tablet, was also observed and noted.

\subsubsection{Semi-structured interview}

After interacting with the AR application, participants were invited to partake in a semi-structured interview that was audio taped, which focused on revealing their comprehension of the original architectural context, particularly the aforementioned architectural features and the spatial perception of Room S. More questions were then asked to open up the interview towards more qualitative answers, such as the participants' impressions of using such technology in museums (e.g., what they liked, what they disliked and why).

The interview responses were then manually analyzed using an Excel spreadsheet that contained the different aspects of communicating the architectural context, such as how they described Room $S$ and which architectural features they remembered; averages and medians of estimated dimensions were also calculated. Furthermore, participants' quotations from the interview were manually transcribed and then categorized as what they learned, why they liked it (or disliked it), and their suggestions, as shown in Fig. 7.

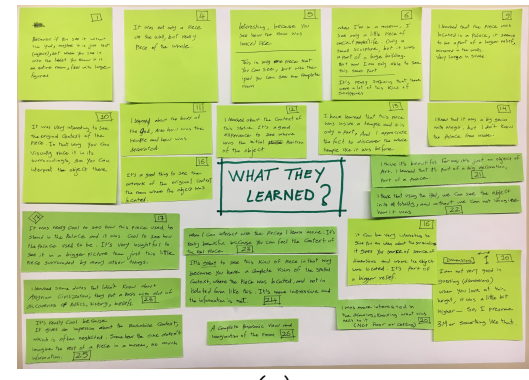

(a)

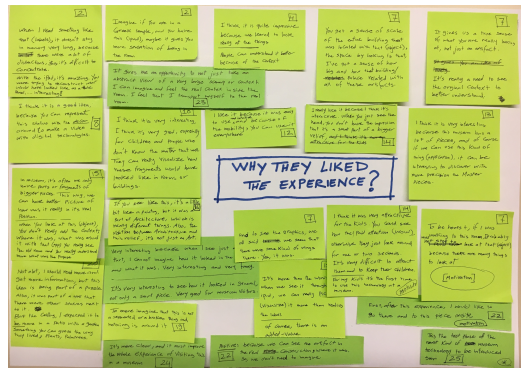

(b)

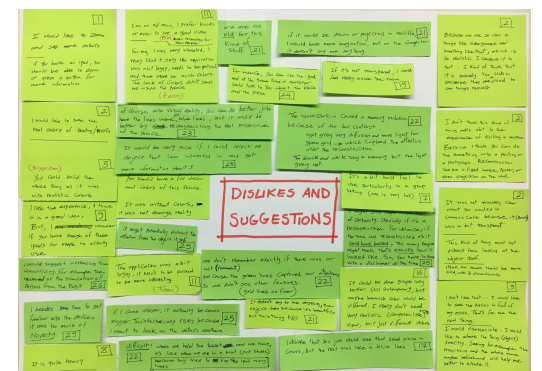

(c)

Figure 7. Extracting quotations from interview transcripts: (a) what they learned from this experiment, (b) why they liked this experience, and (c) what they disliked and their suggestions for improving the experience.

\subsubsection{Sketching}

We also used sketching as a complementary method to reveal how participants remembered the architectural context. After their verbal descriptions of Room S during the interview, they were asked to sketch the appearance of Room S (e.g., shape and elements, etc.) using two papers, one in two dimensions for the close surroundings of the artifact on the same wall (Fig. 8a), and the second in three dimensions for a bigger image of the entire room where the artifact was located (Fig. 8b). 


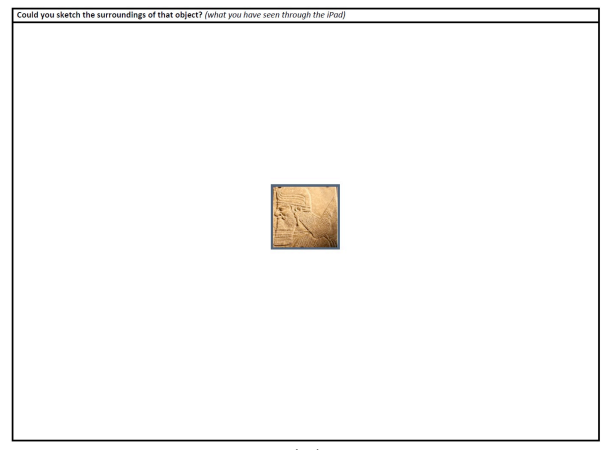

(a)

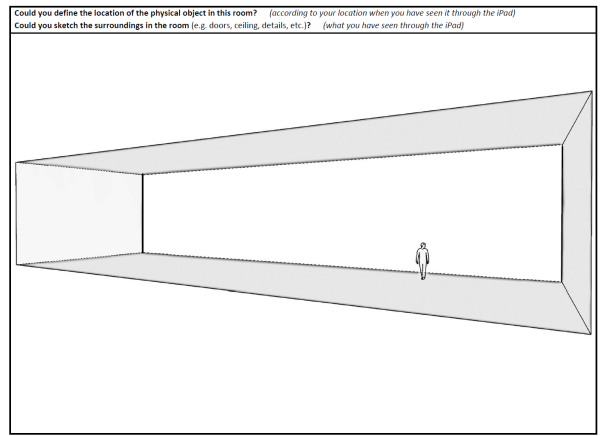

(b)

Figure 8. Sketching the architectural context of the artifact: (a) 2D sketch paper for the close surroundings of the artifact on the same wall, and (b) 3D sketch paper for a bigger image of the entire room where the artifact was located.

From their drawings, we manually extracted which of the five architectural features they remembered and graphically reproduced. We then compared the features extracted from sketching to the features mentioned in their verbal description. More details were also extracted from their drawings, such as whether they drew the wing(s) of the genius, and/or his body, or how other figures on the adjacent reliefs stood in relation to our museum artifact.

\subsubsection{User experience questionnaire}

The interview was followed by a concise user-experience questionnaire, which allowed participants to express their impressions or attitudes that emerged when they interacted with the AR application. It contained items to measure how the application was enjoyable, inventive, good, easy, motivated, efficient, attractive and informative. The items were scaled on a 7-point Likert scale, from -3 (representing the most negative answer) to +3 (representing the most positive answer), when 0 is a neutral answer.

\subsection{Evaluation study}

The evaluation study commenced with a low-fidelity test at our research lab with only a few participants, which was followed by a one-day pilot study in the real museum environment. Thereafter, we carried out the actual study for approximately two weeks. All participants signed an informed consent form to confirm that they voluntarily participated and that the results of this research would be used only for scientific purposes.

\subsubsection{Pilot study}

Our one-day pilot study in the main exhibition room of the Near-Eastern collections at RMAH aimed to reveal usability issues in an ecologically valid context, such as whether lay museum visitors could intuitively understand how to interact with the AR application. Here, each participant was introduced by a brief explanation about the exhibited object (its historical period) and the purpose of interacting 
with the AR application (to explore the original architectural context of the object). The pilot study included 10 participants, who participated individually or in groups, including couples and families.

\subsubsection{Actual study}

Based on the results of the pilot study, several modifications were implemented, such as: 1) adding an animated illustration as a pop-up in the application (Fig. 9) to stimulate participants to look around and see the entire Room S, when they had looked at the artifact for more than 7 seconds without rotating, and 2) changing the transparency of the digital reconstruction to be more opaque, so as to ensure better visualization of the architectural features. The final study was deployed at different times to maintain ecological validity (i.e. mornings and afternoons) over a total period of two weeks to reach varied types of museum visitors (i.e. local and international visitors, and different age groups).

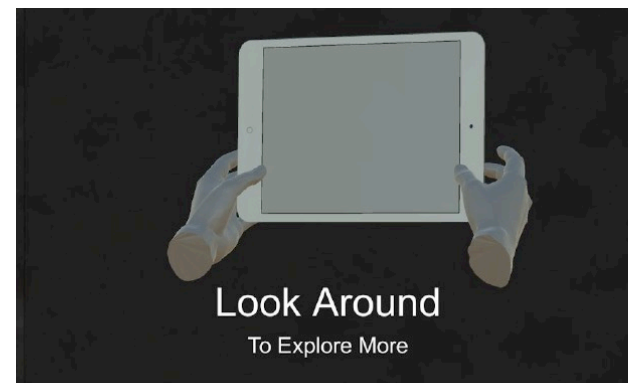

(a)

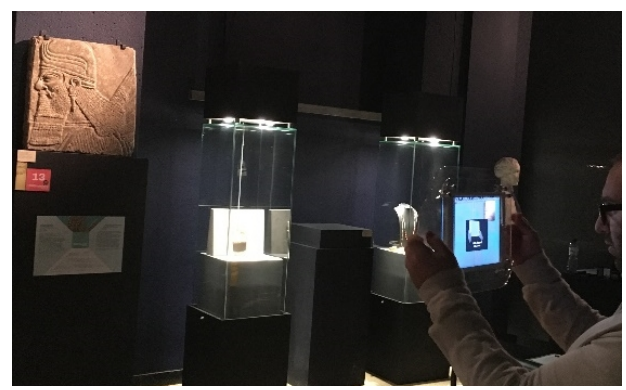

(b)

Figure 9. Animated illustration that pops up to participants to stimulate them to look around when they look at the artifact without rotating: (a) a close-up of the pop-up, and (b) the illustration pops up to one participant.

\section{RESULTS}

The final study involved a total of 26 questionnaires from visitors who participated individually (15) or in groups (11) with a total number of 46 museum visitors. They formed disproportionate user groups, as they varied in gender (i.e. 22 males and 24 females), age range (i.e. 8 children, 3 teenagers, 29 adults, and 6 elderly), and the purpose of their museum visit (i.e. 5 family visits, 6 local tourists, 13 international tourists, and 2 museum staff members).

We categorized our results into two sections: (a) how the AR experience enabled participants to contextualize the artifact into Room $S$ in terms of the architectural features and the spatial dimensions, and (b) the usability of the AR experience and how it engaged the participants (i.e. museum visitors).

\subsection{Contextualizing the original architecture}

After the Conventional Visit, participants who read the text label could understand the general information about the object, i.e., that it was a relief from Nimrud's Northwest palace and that it was from the Neo-Assyrian period. Most of the participants $(20, N=26)$ assumed that the object was part 
of a bigger relief, but they could not imagine the architectural context of the space where the object was located.

On the contrary, after the AR Visiting Experience, their perceptions about the context changed: "I learned that the piece was located in a palace, it seems to be a part of a larger relief" (participant 9). Some even compared it to their Conventional Visit, such as "it is very insightful to see it in a bigger picture than just this little piece surrounded by many other things" (participant 17), and how it positively affected their perception about the larger context: "when I see just a small part, I cannot imagine how it looked in the past and what it was, but now it is very interesting to see how it looked in general, not only a small piece ... very good for museum visitors"(participant 18), and "it is really cool because it gives an impression about the plausible context, which is often neglected. Somehow one does not imagine the rest of a piece in a museum"(participant 25).

From their verbal descriptions of Room $S$, we extracted the various architectural features they remembered. Most of the participants $(20, N=26)$ described Room $S$ as a large rectangular space, including many other reliefs on stone panels against the walls; they also mentioned that there were some arched gates connecting Room $S$ with the adjacent spaces. 15 participants ( $N=26)$ mentioned the horizontal frieze, in an Assyrian pattern, above the reliefs. Participants seemed to focus less on the ceiling beams and floor tiles; only nine and seven $(\mathrm{N}=26)$ mentioned them respectively.

It is also worth mentioning that when we invited the participants to sketch the surroundings, more information was revealed than from their verbal descriptions. Fig. 10 shows a comparison of the different architectural features of Room $S$ between participants' sketching and their verbal description.

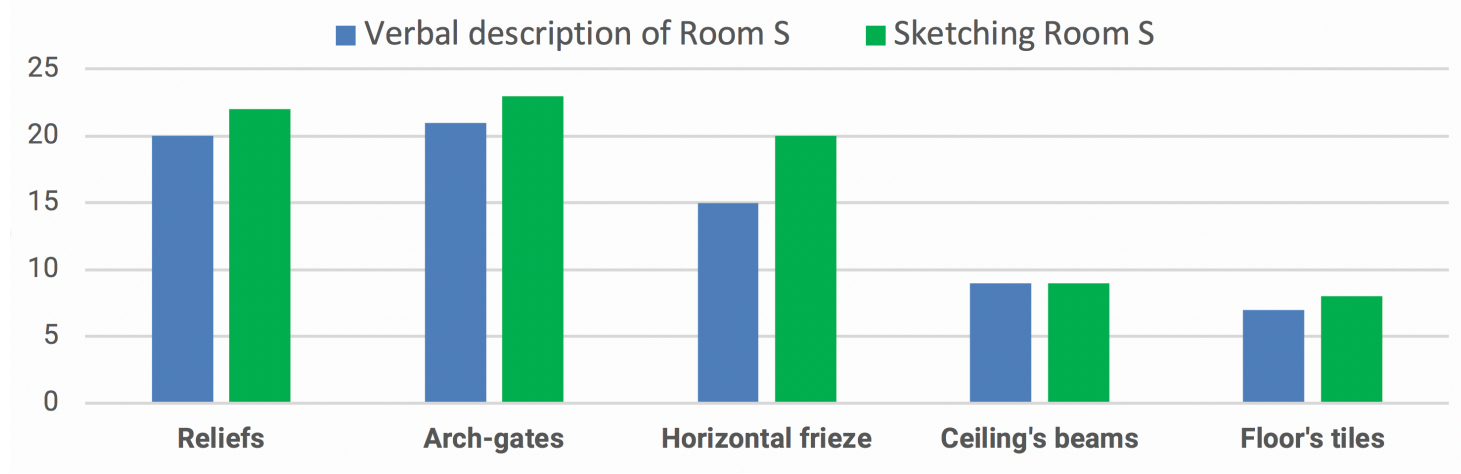

Figure 10. Participants' descriptions of the different architectural features of Room S, from their verbal descriptions (in blue) and from their sketching (in green). The $Y$-axis indicates the number of participants describing the corresponding architectural feature.

We divided the results of the participants' drawings into 3D sketching that focused more on architectural features and 2D sketching that focused more on embellishment. Fig. 11 shows samples of some participants' sketching, which reveal the different levels of recalling these architectural features. These sketches depict the location of the physical artifact in Room $S$ and how it relates to other panels and reliefs, sketched by 22 participants (Fig. 11a, 11b and 11c). Other architectural features such as the arched gates, were sketched by 23 participants, while the horizontal frieze was sketched 
by 20 participants. Only nine participants sketched the ceiling beams and 8 participants sketched the floor tiles. This lower amount of sketching the beams and the tiles might well be due to the fact that only a few participants looked up and down during their interaction.

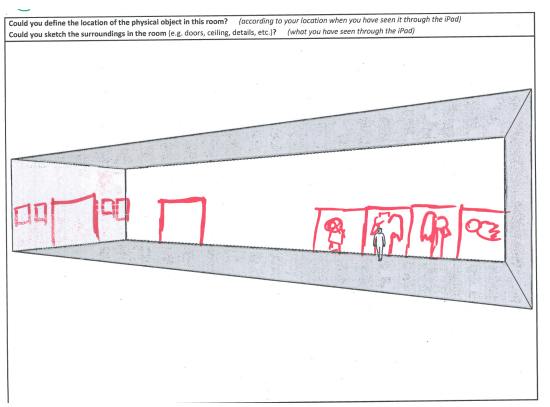

(a)

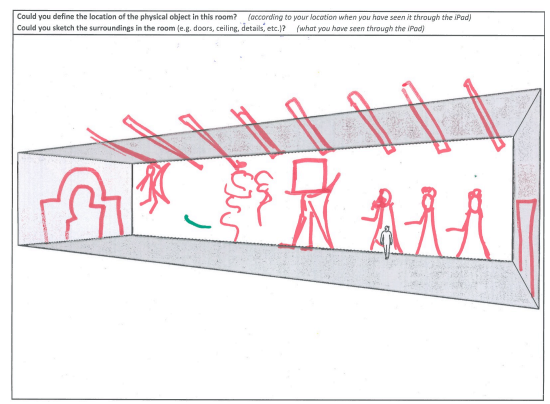

(b)

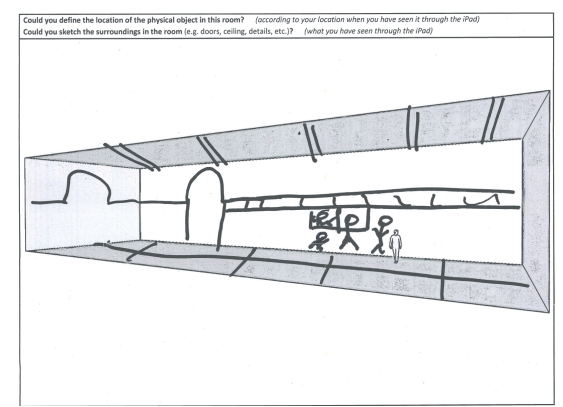

(c)

Figure 11. Samples of participant's sketches who focused more on the architectural features: (a) sketching the different panels corresponding to the location of the physical artifact (participant 6), (b) sketching more architectural features such as the arched gates and the ceiling beams (participant 14), and (c) sketching the five architectural features discussed above, including the horizontal frieze and the floor tiles (participant 10).

In addition to recalling the architectural features, sketching the 2D paper revealed more details about the embellished drawings that participants perceived and remembered. For instance, 22 participants $(\mathrm{N}=26)$ drew the completion of the genius's body (Fig. 12a, 12b and 12c); 13 participants recalled that the relief is of a winged genius, and they accordingly drew the wing(s) of the genius (Fig. 12b and 12c), while only four participants recalled that the figures were mirrored in the different panels (Fig. 12c).

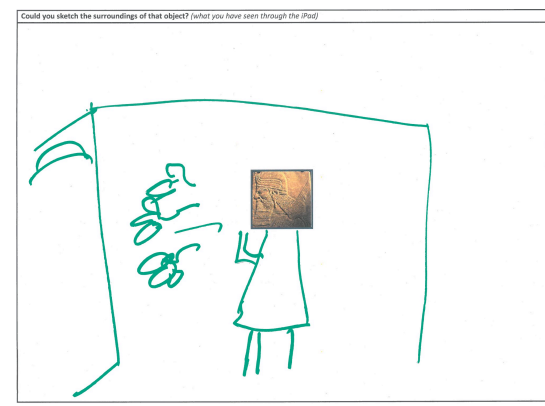

(a)

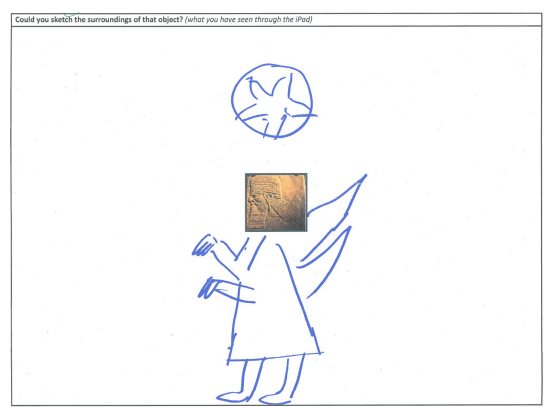

(b)

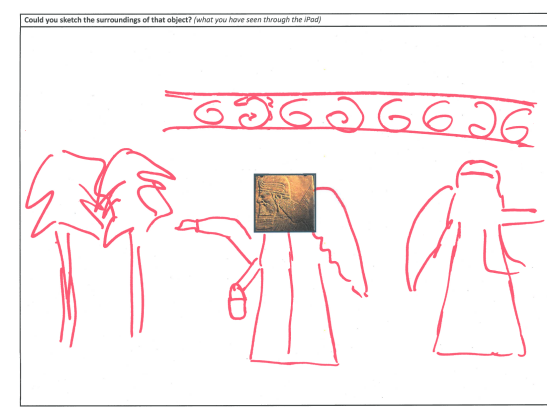

(c)

Figure 12. Samples of sketches by participants who focused more on the embellishment: (a) sketching the body of the genius (participant 22), (b) sketching the body with the genius's wings and a representation of the frieze above (participant 24), and (c) sketching the body with a wing and how it related to the other drawings on the side panels (participant 20).

Spatially, participants described Room $S$ as a large rectangular space. Their estimation of its height varied from $4 \mathrm{~m}$ to $10 \mathrm{~m}$ with an average of $6.3 \mathrm{~m}$ (median is $5 \mathrm{~m}$ ), which is very close to the actual height of Room $\mathrm{S}$ in our digital reconstruction $(6.5 \mathrm{~m})$. Their average estimated width of Room $\mathrm{S}$ was $8.7 \mathrm{~m}$ (median is $7 \mathrm{~m}$ ), which also comes close to the actual width $(9.5 \mathrm{~m})$, varying from $5 \mathrm{~m}$ to $20 \mathrm{~m}$. While participants varied in their estimations of the length of Room $\mathrm{S}$ from $10 \mathrm{~m}$ to overestimations 
nearing a hundred meters, with an average of $35.8 \mathrm{~m}$ (median is $16.5 \mathrm{~m}$ ), the actual length is $30 \mathrm{~m}$. Table 1 summarizes the actual and estimated dimensions of Room $\mathrm{S}$, calculating the error range.

Table 1. Actual and estimated dimensions of Room S.

Dimensions of Room S
\begin{tabular}{|l|l|l|l|}
\multicolumn{1}{c}{ Actual dimensions } & Estimated dimensions (avg.) & Error range \\
\hline Height & $6.5 \mathrm{~m}$ & $6.3 \mathrm{~m}$ & $-3 \%$ \\
\hline Width & $9.5 \mathrm{~m}$ & $8.7 \mathrm{~m}$ & $-8 \%$ \\
\hline Length & $30 \mathrm{~m}$ & $35.8 \mathrm{~m}$ & $+19 \%$ \\
\hline
\end{tabular}

The spatial estimations are very close to the actual dimensions as illustrated in Fig. 13. The error range of the average estimation of the length of Room $S$ is relatively higher than the error range of estimations of both height and width, as indicated in Table 1. This mis-estimation of length might well be a result of the rectangularity of Room S, especially because participants were positioned near the end of the room. Rectangularity produces substantial illusion, as more rectangular rooms consistently are estimated as larger than less rectangular rooms of equal size [Sadalla and Oxley 1984]. We then could make a potential generalization of these results, i.e. that AR could be an appropriate medium to communicate the spatial dimensions of a square or less-rectangular space that communicates the heritage's lost context.

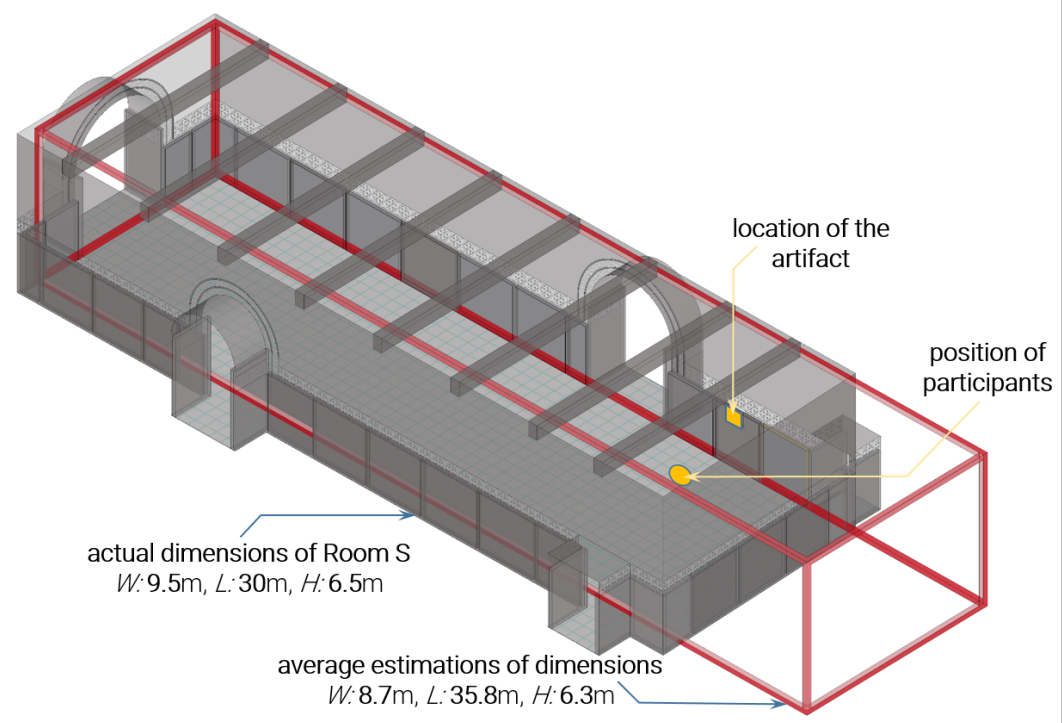

Figure 13. The participants' average estimations of dimensions (in red) compared to the actual dimensions of Room S.

\subsection{User experience}

We report in this section on the user experience in terms of the apparent focus of attention during interaction, the participants' answers on the user experience questionnaire, and their forms of engagement and appreciation. 


\subsubsection{Focus of attention}

Participants focused their attention on varying angles of view during the interactive exploration process. Fig. 14 shows a top view of a participant holding the tablet, demonstrating the focus intensity for looking at the various angles of view during the interaction. Consequently, more arcs (i.e. number of participants) can be noticed in the angles on the front side, close to the exhibited artifact, while only a limited number of participants (i.e. 27\%) looked at the back side of Room S during their Initial Interaction (Fig. 14a), despite of the animated pop-up. In comparison, after the Guided Interaction (Fig. 14b), more participants looked at the other sides of Room S (i.e. around 90\% at the left and right sides, and around 70\% at the back side). In both Initial and Guided interaction (Figs. 14a and b), most people looked at the left side of Room S more than the right side. This might well be the result of the position of participants and the location of the artifact in Room S (Fig. 13), as the larger part of the space can be seen from the left side. It might also be a result of the physical museum environment, as on the left side some other Assyrian artifacts were exhibited, which might stimulate participants to look more towards the left (Fig. 1b).

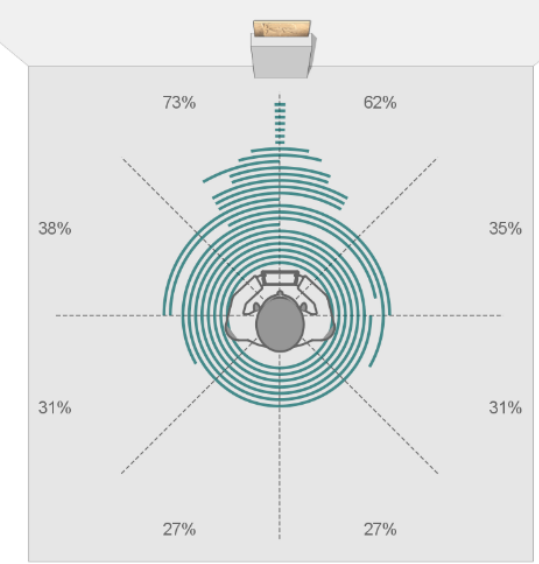

(a)

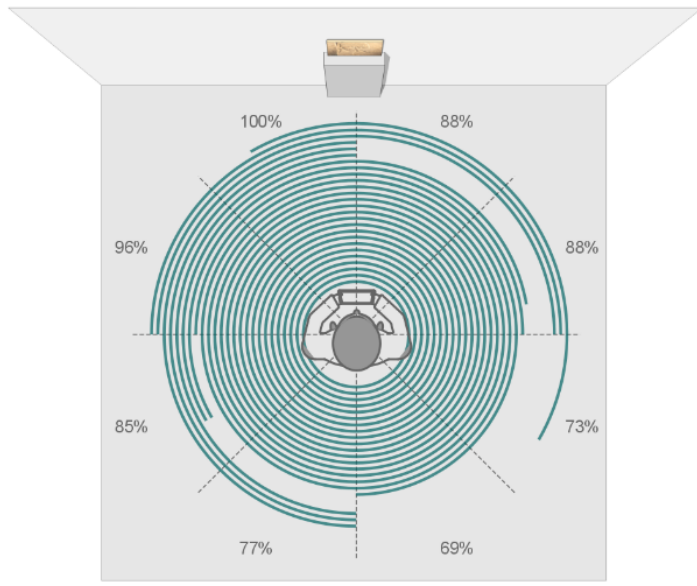

(b)

Figure 14. Participants' focus of attention in terms of 'angle of view' in their AR experience (each green arc represents the total angle of view of one participant, indicating the percentage of participants for each angle): (a) is an Initial Interaction, while (b) is a Guided Interaction after telling them that they can look around.

When we compared the angles of view to the perception of the architectural features, we noticed that participants who restricted themselves to a limited angle of view described fewer architectural features during the interview and in their sketching. We also noticed that participants who had a limited angle of view during their Initial Interaction participated individually. Other participants, who had $360^{\circ}$ interaction, mostly participated in groups. We therefore hypnotize that participating in groups encourages visitors to explore more by looking around, having an inclusive view of Room S.

Further, we observed that only a few participants looked up $(8, \mathrm{~N}=26)$ or down $(8, \mathrm{~N}=26)$ during the interaction. This might well be the cause of less perception of the ceiling beams and floor tiles (Fig. 10). With regard to the movement of participants during the interaction, we noticed that most of them $(18, N=26)$ were steady - they did not move - while other participants $(8, N=26)$ started to move a few 
steps, mainly forward and to the left side. One of them even moved until he reached the physical object and then moved all over the space. Comparing the movements of participants around the space to their answers during the interview, we noticed that those who moved around perceived more architectural features from their verbal descriptions and from their sketching as well.

\subsubsection{User engagement}

In general, individual participants spent less time interacting (112s, avg.) in comparison to groups of participants (140s, avg.), as the discussion between group members encouraged them to look around and to explore more. We also noticed that children (i.e. <12 years old) spent more time in their interaction (140s, avg.) than the elderly in particular (95s, avg.). Besides the time of interaction, the elderly (i.e. > 65 years old) seemed to appreciate the AR experience less (two older participants did not like it; "we are too old for this kind of stuff"(participant 21). Elderly participants preferred to focus their attention on the physical object rather than looking at the context through a display: "I don't like it, I would like to see the pieces in front of my eyes ... that's for me the real thing, I would like to admire the object directly" (participant 3). Children, on the other hand, liked the AR experience much more because they found it attractive; a mother with three kids commented that "it is very difficult to attract children, and you can see how they paid attention, otherwise they would just look around for one or two seconds" (participant 14). Fig. 15 shows the number of participants at different levels of appreciation.

Figure 15. Levels of appreciation of the AR experience, showing the number of participants for each level.

\subsubsection{User experience questionnaire}

The results of the user experience questionnaire (Fig. 16) convey the usability of our AR application and the participants' attitudes toward using it. Most of the participants (24, N=26) found the application good; "it is very good, especially for children and people who do not know the matter that well ... they can really visualize how these fragments would have looked like in rooms or buildings" (participant 10). Likewise, 24 participants found it inventive; one participant even commented that "I needed some time to get familiar with the device, it was too much of novelty" (participant 25). 23 participants $(\mathrm{N}=26)$ also agreed that the application was motivating them to visit the object and interact with it: "to be honest, if I was walking to this room, I would probably not stop at that object because there are many things to look at" (participant 7). Their motivation even extended beyond their museum visit; "after this experience, I would like to go there and to see this piece onsite" (participant 22); that participant most likely did not know that the remnants of the original palace were recently destroyed. 22 participants $(\mathrm{N}=26)$ considered it attractive as well, particularly children and young museum visitors, validating the results from the previous section. Participants $(23, \mathrm{~N}=26)$ believed that the application was informative: "in this museum, it is really hard to interpret the objects ... these are here just pieces of stone exhibited against the walls ... but actually through the application, it is quite important to know that they were part of a big building" (participant 10). However, more participants disagreed with the ease and clarity of the application. It seemed that unclarity issues resulted from the abstract visualization; for instance, three participants found it unclear: "it was not absolutely clear what you wanted to communicate because it (panels) was a bit 
transparent"(participant 2), who continued, "this kind of application must not distract from looking at the object itself." Moreover, one participant thought that the application was difficult because (s)he tried to flip the tablet several times, so the visualization was a bit laggy: "when we hold the tablet and we move, it is like we are in a boat"(participant 22). Another participant could hardly see the tablet's screen, which was held by his group-mates, who were relatively shorter than him. He commented that "it is a bit hard tool to use, particularly in a group setting"(participant 7).

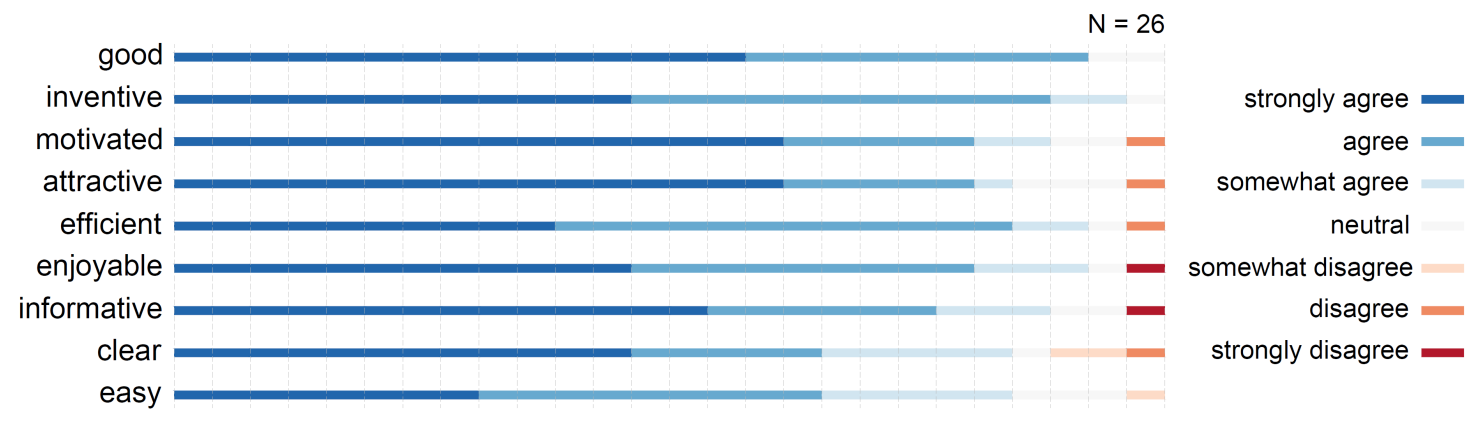

Figure 16. Results of the user experience questionnaire; each row shows an item scaled from strongly agree (blue) to strongly disagree (red), while each cell represents the answer of one participant.

\section{DISCUSSION}

In this section, we discuss the implications of the previous results with relevance to future research or potential further development of AR applications that communicate heritage in museum environments. We explain the qualities of using AR in museums, such as how it positively affects visitors' memorability of architectural qualities, and how it provokes their curiosity to explore further and/or get more information. We highlight some considerations about AR visualization, such as how levels of embellishment direct a user's focus of attention, and which aspects should be considered when using AR abstract visualization to communicate heritage. We outline several design recommendations to overcome current AR usability issues in museums about intuition, freedom of movement, and age-related differences.

\subsection{AR communication in museums}

\subsubsection{Usability issues}

AR navigation in museums seems to be insufficiently intuitive for lay visitors. Part of our AR experience was meant that participants should look around during their interaction and to look at Room S from different points of view. However, results show that only a few participants (i.e. 27\%) looked at the back side during their Initial Interaction, despite the animated illustration that urges them to look around. In terms of usability, AR interaction was less intuitive because of the time needed to start navigation and begin looking around: "I needed some time to get familiar with the device, it was too much of novelty" (participant 25). As a possible solution, we provided them with verbal instructions to look around that enhanced their AR experience. For other participants, who are used to touch screens, assumed that there would be more functions on the tablet display, such as 
rotating and zooming: "I would like to zoom and see more details ... if you have an iPad, you should be able to zoom or press a button for more information" (participant 1). Consequently, we recommend that AR experiences in museums should consider including some kind of instructions to overcome the usability issues. In a museum environment, gaming strategies or honeypot effect might be suited, where visitors interacting with the application passively stimulate other visitors to observe, approach and engage in an interaction [Wouters et al. 2016].

\subsubsection{Freedom of movement}

Allowing museum visitors to freely move around during their AR experience should be carefully considered. AR technology is considered an immersive experience [Dunleavy et al. 2009] because whenever users hold the tablet, their attention is drawn to the screen. In our study, the area around the artifact was relatively spacious, allowing visitors to move forward and backward and to look at the artifact from different points of view. Results show how this freedom of movement led to better communication of the architectural qualities in terms of perceiving and remembering the architectural features. In other scenarios, however, visitors' freedom of movement might be quite risky; because of the priceless artifacts that are exhibited in the vicinity, visitors might hit them inadvertently. Because freedom of movement during the AR experience causes a better communication of architectural context, we recommend that museum visitors are able to walk around. Yet the physical surroundings should be carefully considered when using such AR experiences in a museum environment. For instance, dense and narrow spaces should be certainly avoided.

\subsubsection{Curiosity}

Using AR in museums stimulates the curiosity of visitors, and they realize new insights that cause an exploration of information that is not necessarily available within the AR environment. It is suggested that AR experiences in museums should encourage visitors to seek more information about the museum artifacts [Tillon et al. 2011]. But the issue is whether this information should be accessible or not. Providing the desired information will increase the appetite for visitors to stay informed, but doing so will also inevitably interrupt the immersion, as the new information will need to be shown via images, text or audio. In our study, because of the low-fidelity prototype, many participants expected 'more,' particularly in terms of the information that was offered: "you can use the iPad and at the same time a narrator could talk to you about the palace and the piece"(participant 24) and "if I could select an object that I am interested in, and get more information"(participant 23), as well as in terms of interactive features, such as "the movement or the simulation of persons from the past" (participant 26). Accordingly, we recommend that AR should be used in museums to stimulate different forms of curiosity about the architectural, historical or social contexts. This quality should be further investigated and benchmarked versus more common informative approaches.

\subsubsection{Age-related differences}

We also believe that the current AR museum experience does not suit well all age groups of visitors. Based on our results, AR seems to be less appreciated by elderly people: "I am an old man, I prefer 
books or even to see a good video" (participant 11). Disliking the AR experience arises only from elderly people (Fig. 15). On the other hand, younger participants, particularly children, appreciated the application more and the whole experience attracted and motivated them to interact and to acquire the knowledge in an indirect manner. Previous HCI studies on the effect of user age show that small screen sizes and complexity cause more difficulties for elderly people in browsing smartphone interfaces [Al-Showarah et al. 2014]. Elderly people also may have decreased capabilities for interfaces that require motor actions of the neck and face [Hands and Stepp 2016]. From our evaluation study, we noticed that elderly participants looked up and down less during their interactions. Accordingly, we propose that an AR museum experience should take into consideration the age-related differences of visitors. For instance, less complex interfaces and larger screens should be used, and the targeted artifacts should be neither relatively low nor relatively high, in order to to decrease the required neck motor actions.

\subsection{Memorability}

The use of AR in a museum environment positively affects the memorability of visitors. In particular, it influences how they perceive and recall architectural features and spatial dimensions. Previous research [Juan et al. 2014; Hou and Wang 2013] also shows that AR is more effective in retaining the information in the short-term memory, as it enhances spatial comprehension and improves cognitive transformation.

Memory is a cognitive process that is crucial for the appropriate learning or understanding of any knowledge. AR museum studies demonstrate that AR enhances visitors' understanding of the meanings of museum artifacts (e.g. [Tillon et al. 2011]), and thus their memory. In our study, although most of participants had read the text labels, only a few of them remembered what was written when we asked them what they learned from their first Conventional Visit: "when I read something like that (text labels), it does not stay in my memory very long" (participant 2). However, after the AR Visiting Experience, our results showed how they remembered several architectural features of Room S in addition to the drawings' details. Our findings also show how the AR experience enabled participants to perceive and to accurately estimate the dimensions of Room S, as illustrated in Fig. 13. Yet, participants did not perceive nor remember well some architectural features, such as beams and tiles. This might have happened because only a few participants looked up and down during their interaction.

Therefore, we recommend that AR could become an effective medium to convey the architectural features and spatial dimensions of museum artifacts and their related contexts. Nevertheless, further investigations are also encouraged, to evaluate whether this short-term memory might well lead to longer-term memory. Heritage communication should not be only about remembering the information for a short period of time.

\subsection{Levels of embellishment}

The visitor's focus of attention is directed by the levels of embellishment in AR visualization. In this study, the functional aspects of Room $S$ were visualized in a relatively low embellishment level. 
However, our visualization of Room S comprised a higher level of embellishment for the detailed drawings of the different reliefs.

During the evaluation study, we were surprised by the amount of embellished details that participants recalled and even sketched. Their verbal description and their sketching of the original context were diverted more towards the fine details of the drawings, such as the wing of the genius and other drawings (Fig. 17b) than the functional aspects (Fig. 17a). One participant, when he was asked during the interview whether he remembered any functional aspects in the ceiling or the floor, he replied "I was more interested in the drawings"(participant 20). Literature also proves that people tend to remember the content of embellished visualization better [Borgo et al. 2012], because embellishment is a cognitive difficulty, causing more cognitive processing. This means that the more embellished the visualization is, the more difficult it is to be understood but it is easier to be remembered.

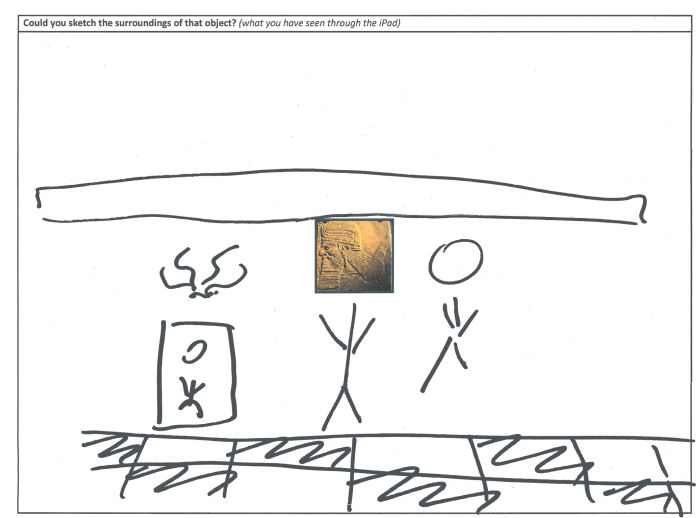

(a)

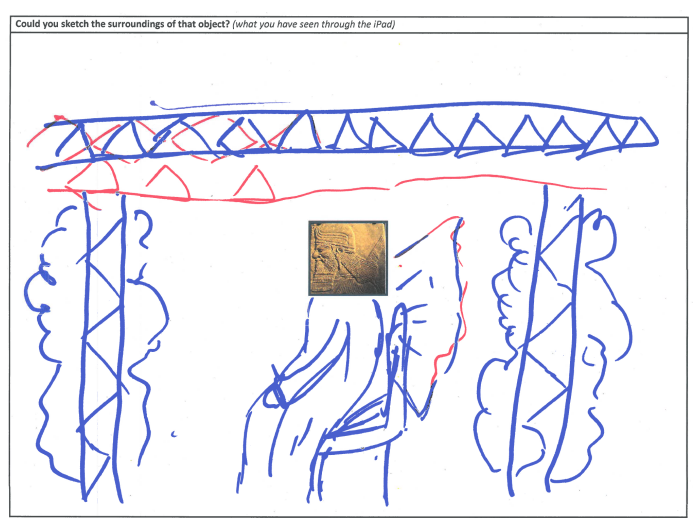

(b)

Figure 17. Two samples of participant's sketches of the close context: (a) by a participant who focused on the functional and architectural aspects by sketching the floor, the horizontal strip representing the frieze, an abstraction of the gateway and abstract figures (participant 10), while (b) is by a participant who focused more on the embellished details by sketching the body with the genius's wings, with a more detailed representation of the horizontal frieze and how it related to the other drawings on the sides (participant 2).

Accordingly, we recommend that the levels of embellishments in AR visualization should be mapped to the user's focus of attention. If we had embellished the room too much, the focal point of the spatial qualities might have been diminished. Yet the choice of the different levels of embellishment might well depend on the specific focus of the intended communication. For instance, when it is expected that museum visitors should focus on the drawings, then a more embellished representation for the drawings might be more suited. Nevertheless, an equilibrium ought to be sought, because more embellished AR visualization could become overwhelming or difficult to understand.

\subsection{Abstract visualization}

Aspects of transparency and choice of colors affect how users appreciate AR abstract visualization. Although all participants understood the original architectural context of the artifact and correctly described the prominent architectural features of Room S, even so 11 participants $(\mathrm{N}=26)$ preferred to 
see a more realistic view instead of the abstract visualization: "I would like to see the real colors of paintings (reliefs)" (participant 2). That might be because visitors are used to realistic visualization "because we are so used to things like videogames and similar things, which is so realistic. I compare it to that and I think it is probably too static"(participant 2).

The semi-transparency of the visualization seemed to be one of the reasons that made some participants appreciate the abstraction less: "it was not absolutely clear what you wanted to communicate because it was a bit transparent"(participant 2). And it might have lowered the user's level of immersion: "if it is not transparent, I would feel really inside the room" (participant 19). Moreover, the choice of colors seemed to negatively affect the AR experience with the abstract visualization: "I dislike that you just could see that small piece (relief) in colors, but the rest was like in blue lines"(participant 17). In particular, they suggested that the choice of the cyan color made the abstract visualization less preferable: "it could be done graphically better ... still contemporary, but maybe brownish color would be different. I really do not need a very realistic computer-like environment view, but just different colors" (participant 16). More specifically, the use of highcontrast colors (i.e. cyan) to highlight specific features (i.e. tiles and beams) seemed to hinder the communication of other features that were visualized in lower contrast: "the visualization caused a memory problem because of the low contrast. Black and white (frieze) stayed in memory, but the light grey did not because of the diffusion, and the green (cyan) grid captured the attention over the reconstruction (light grey)"(participant 22).

On the other hand, we believe that abstraction holds several advantages in an AR experience, such as how to visualize uncertain information. Realistic visualization might give museum visitors a false impression of certainty: "if the room was reconstructed as it could have looked, too many people might think that is exactly how it looked like"(participant 25). For instance, adding any more detailed information to the reconstruction of Room S would be guessing, because although we know how the basic outlines of the drawings were, there could have been some other features in the room itself that we do not know about. In this case, many visitors might think that the visualization is exactly how Room $S$ appeared, but it is only how it could have looked.

Consequently, AR abstract visualization might be suited for communicating uncertain heritage information. As such, we propose that the level of abstraction in AR visualization should correspond to the level of information certainty. Aspects of transparency and choice of colors should be carefully considered in the visualization design. For instance, all the required features to be communicated should be visualized in higher-contrast colors compared to other features.

\subsection{Sketching as an evaluation method}

Sketching is a suitable evaluation method to capture the perception and memorability of contextual information, such as architectural features. As such, it can be used in other studies that focus on the communicative effectiveness of qualities that relate to space.

Although most participants initially hesitated to sketch the surroundings, perhaps due to a sense of social embarrassment or self-perceived poor drawing skills, almost all participants eventually sketched the surroundings of Room S. Participants also tended to recall more architectural features while they were sketching, as is illustrated in Fig. 10. Furthermore, sketching obviates language 
concerns between researchers and participants. For instance, the horizontal frieze was mentioned in the verbal description by only 15 participants, while it was sketched by 20 ( $\mathrm{N}=26)$. Perhaps when they started to draw the panel, the inclusive visual image became clearer in their minds.

Accordingly, we propose that sketching should be considered as a complementary evaluation method for future experiments that communicate heritage in museums. Further studies are encouraged that would investigate whether sketching could also stimulate visitors to report on other types of heritage information (e.g. cultural and social), and whether sketching should be always accompanied by verbal descriptions or should it be a stand-alone evaluation method.

\subsection{Shortcomings and limitations}

In this study we realize that the conclusions concerning information conveyed via an AR application might be limited to the communication of the original context of heritage museum artifacts. For instance, we deployed the experiment for a relatively short time with a limited number of participants who had different backgrounds and varying degrees of expertise. The chosen artifact was located originally in a museum exhibition room that was quite dark. At the same time, we believe that most of our findings and discussions can be generalized towards many other forms of AR that are meant to communicate heritage information to a lay audience.

Concerning estimating the dimensions of Room S, the medium and techniques we used (i.e. mobile $\mathrm{AR}$ ) to represent the space might not be the only factor that affects spatial cognition; people generally differ in the way they perceive spaces and accordingly how they estimate spatial dimensions. For instance, architects are skilled in perceiving spaces and they are very familiar with estimating dimensions compared to other museum visitors. As we did not normalize the participants according to their professions or backgrounds, we recommend that these aspects should be further investigated in order to learn to what extent they affect the spatial cognition of museum visitors.

Moreover, on busy museum days with large crowds, AR might not be ideal, as queues could form: "I like the experience, I think it is a good idea, but I wonder if you have enough iPads for people to actually use"(participant 9). One could argue that commercializing the application could resolve this issue, including many more museum artifacts, which visitors could use for any of the masterpieces displayed in various museum departments. However, a downloadable smartphone application will bring many visitors at once, who would potentially bump into each other. By limiting the number of devices there might be queues, but many fewer usability concerns.

\section{CONCLUSION}

In this paper, through a field study in a real-world museum environment, we deployed a mixedmethod evaluation methodology to investigate how AR enhances the communication of the architectural context of an isolated artifact. Our chosen artifact is a relief from the Nimrud palace in Iraq, exhibited at the Royal Museums of Art and History in Brussels. It is considered an exceptional museum artifact due to the recent deliberate destruction of its original context.

We conclude the paper with a set of discussion points and design recommendations for future research or potential further development of $\mathrm{AR}$ applications that communicate heritage in 
museums. Our findings show several reasons for using AR in museums, such as its positive effect on visitors' ability to remember architectural qualities, particularly how they perceive and recall architectural features and spatial dimensions. Using AR in museums also stimulates the visitors' curiosity to explore more information. Several considerations about AR visualization are highlighted as well, such as how levels of embellishment direct the user's focus of attention. For uncertain heritage information, AR abstract visualization might be suited for communication, but aspects of transparency and choice of colors should be carefully considered. We outline several design recommendations to overcome current AR usability issues in museums, including intuition, freedom of movement, and age-related differences.

\section{ACKNOWLEDGEMENTS}

We would like to thank the Antiquity Department of the Royal Museums of Art and History in Brussels, specifically Dr. Bruno Overlaet for the support and assistance during the museum experiment. We would like also to thank all the volunteers for their participation during their museum visit. The corresponding author gratefully acknowledges the PhD scholarship funded by the Egyptian Ministry of Higher Education.

\section{REFERENCES}

Suleyman Al-Showarah, Naseer AL-Jawad and Harin Sellahewa. 2014. Effects of user age on smartphone and tablet use, measured with an eye-tracker via fixation duration, scan-path duration, and saccades proportion. In: C. Stephanidis and M.Antona (eds) Universal Access in Human-Computer Interaction. Universal Access to Information and Knowledge. UAHCI 2014. Lecture Notes in Computer Science, 8514, 3-14.. Springer: Cham, CH. DOI: https://doi.org/10.1007/978-3-319-07440-5_1

Anastassia Angelopoulou, Daphne Economou, Vassiliki Bouki, Alexandra Psarrou, Li Jin, Chris Pritchard and Frantzeska Kolyda. 2012. Mobile augmented reality for cultural heritage. In: N. Venkatasubramanian, V. Getov and S. Steglich (eds) Mobile Wireless Middleware, Operating Systems, and Applications. MOBILWARE 2011. Lecture Notes of the Institute for Computer Sciences, Social Informatics and Telecommunications Engineering, 93, 15-22. Springer: Berlin, Heidelberg. DOI: https://doi.org/10.1007/978-3-642-30607-5_2

Ronald Azuma, Yohan Baillot, Reinhold Behringer, Steven Feiner, Simon Julier and Blair MacIntyre. 2001. Recent advances in augmented reality. IEEE Computer Graphics and Applications, 21, 6 , 34-47, DOI: https://doi.org/10.1109/38.963459

Rita Borgo, Alfie Abdul-Rahman, Farhan Mohamed, Philip W. Grant, Irene Reppa, Luciano Floridi and Min Chen. 2012. An empirical study on using visual embellishments in visualization. IEEE Transactions on Visualization and Computer Graphics, 18, 12 2759-2768. DOI: 10.1109/TVCG.2012.197

Daniele Cerra, Simon Plank, Vasiliki Lysandrou and Jiaojiao Tian. 2016. Cultural heritage sites in danger: towards automatic damage detection from space. Journal of Remote Sensing, 2016, 8 (9), 781. DOI: http://www.mdpi.com/2072-4292/8/9/781

Kuo-En Chang, Chia-Tzu Chang, Huei-Tse Hou, Yao-Ting Sung, Huei-Lin Chao and Cheng-Ming Lee. 
2014. Development and behavioral pattern analysis of a mobile guide system with augmented reality for painting appreciation instruction in an art museum. Computers \& Education 712014 185-197.. DOI: http://dx.doi.org/10.1016/j.compedu.2013.09.022

Dan Cosley, Jonathan Baxter, Soyoung Lee, Brian Alson, Saeko Nomura, Phil Adams, Chethan Sarabu and Geri Gay. 2009. A tag in the hand: supporting semantic, social, and spatial navigation in museums. Proceedings of the SIGCHI Conference on Human Factors in Computing Systems (CHI '09)1953-1962. DOI: http://dx.doi.org/10.1145/1518701.1518999

Cuneiform Digital Library Initiative (CDLI). 2018. The Northwest Palace at Nimrud, retrieved from: http://cdli.ucla.edu

Areti Damala, Isabelle Marchal and Pascal Houlier. 2007. Merging augmented reality based features in mobile multimedia museum guides. XXI International CIPA Symposium: Anticipating the Future of the Cultural Past, Athens, Greece. pp.259-264, https://halshs.archivesouvertes.fr/halshs-00530903

Matt Dunleavy, Chris Dede and Rebecca Mitchell. 2009. Affordances and limitations of immersive participatory augmented reality simulations for teaching and learning. Journal of Science Education and Technology, 18 (1), pp. 7-22 , DOI: https://doi.org/10.1007/s10956-008-9119-1

Klaudia Englund. 2003. Nimrud und seine Funde: Der Weg der Reliefs in die Museen und Sammlungen (Orient-Archäologie, Band 12), Leidorf.

Gabrielle L. Hands and Cara E. Stepp. 2016. Effect of age on human-computer interface control via neck electromyography. Interacting with Computers, 28 (1), pp. 47-54, DOI:

http://doi.org/10.1093/iwc/iwu030

Lei Hou and Xiangyu Wang. 2013. A study on the benefits of augmented reality in retaining working memory in assembly tasks: A focus on differences in gender. Automation in Construction, 32 (2013), pp. 38-45, DOI: https://doi.org/10.1016/j.autcon.2012.12.007

Christian L. Jakobsen, Jon B. Larsen, Mads Luther Nørlem and Martin Kraus. 2018. Improving user experience for lost heritage sites with a user-centered indirect augmented reality application. In Federica Bressan (Ed.), Acatia Finbow (Ed.), Tim Vets (Ed.), Micheline Lesaffre (Ed.) and Marc Leman (Ed.), Interactivity, Game Creation, Design, Learning, and Innovation, pp. 54-63, Springer International Publishing, DOI: https://doi.org/10.1007/978-3-319-76908-0

M.-Carmen Juan, Magdalena Mendez-Lopez, Elena Perez-Hernandez and Sergio Albiol-Perez. 2014. Augmented reality for the assessment of children's spatial memory in real settings. PLOS ONE, 9(12): e113751, DOI: https://doi.org/10.1371/journal.pone.0113751

Laura King and James F. Stark. 2016. Experiencing the digital world: the cultural value of digital engagement with heritage. Heritage \& Society Journal, 9 (1), pp. 76-101, DOI: https://doi.org/10.1080/2159032X.2016.1246156

Austen Henry Layard. 1849. Nineveh and its remains: with an account of a visit to the Chaldean Christians of Kurdistan, and the Yezidis, or devil worshippers; and an inquiry into the manners and arts of the ancient Assyrians (2 Volumes), London.

Yu-Chang Li, Alan Wee-Chung Liew and Wen-Poh Su. 2012. The digital museum: challenges and solutions. The 8th International Conference on Information Science and Digital Content Technology (ICIDT2012), Jeju Island, South Korea, pp. 646-649. http://ieeexplore.ieee.org/stamp/stamp.jsp?tp=\&arnumber=6269353\&isnumber $=6269316$ Rozhen Kamal Mohammed-Amin. 2015. Augmented Experiences: What Can Mobile Augmented 
Reality Offer Museums and Historic Sites, PhD Thesis at University of Calgary, Alberta, Canada, DOI: http://dx.doi.org/10.5072/PRISM/25067

Nikolaos Mourkoussis, Fotis Liarokapis, J. Darcy, M. Pettersson, Panagiotis Petridis, Paul F. Lister and Martin White. 2002. Virtual and augmented reality applied to educational and cultural heritage domains. In Witold Abramowicz (ed.), Business Information Systems, Proceedings of BIS 2002, pp.367-372, Poznan, Poland.

Kate Nesbitt. 1996. Theorizing a New Agenda for Architecture: An Anthology of Architectural Theory 1965 - 1995. Princeton Architectural Press, ISBN: 156898054X, 9781568980546

Eslam Nofal. 2013. Taking advantages of augmented reality technology in museum visiting experience. 6th International Congress "Science and Technology for the Safeguard of Cultural Heritage in the Mediterranean Basin", Athens, Greece, 22-25 October 2013.

Joan Oates and David Oates. 2001. Nimrud: An Assyrian Imperial City Revealed. British School of Archaeology in Iraq, ISBN: 978-0903472258

Samuel M. Paley. 2002. Creating a virtual reality model of the North-West Palace. Nimrud Conference: New Light on Nimrud, pp. 195-208, London.

Rabee M. Reffat and Eslam Nofal. 2013. Effective communication with cultural heritage using virtual technologies. International Archives of the Photogrammetry, Remote Sensing and Spatial Information Sciences, Volume XL-5/W2, Strasbourg, France, pp. 519-524, DOI: https://doi.org/10.5194/isprsarchives-XL-5-W2-519-2013

Brett Ridel, Patrick Reuter, Jeremy Laviole, Nicolas Mellado, Nadine Couture, and Xavier Granier. 2014. The revealing flashlight: interactive spatial augmented reality for detail exploration of cultural heritage artifacts. ACM Journal on Computing and Cultural Heritage, 7 (2), Article 6, May 2014. DOI: http://dx.doi.org/10.1145/2611376

Edward K. Sadalla, Diana Oxley. 1984. The perception of room size: the rectangularity illusion. Environment and Behavior, 16(3), pp. 394-405, DOI: https://doi.org/10.1177/0013916584163005

Filippo Stanco, Davide Tanasi, Matteo Buffa and Beatrice Basile. 2012. Augmented perception of the past: the case of the Telamon from the Greek theater of Syracuse. In: Grana C., Cucchiara R. (eds) Multimedia for Cultural Heritage. Communications in Computer and Information Science, vol 247, pp. 126-135, Springer, Berlin, Heidelberg, DOI: https://doi.org/10.1007/978-3-642-27978-2_11

Colin Thompson. 2007. The role of the museum in interpretation: The problem of context. International Journal of Heritage Studies, 1(1) 1994 40-5, DOI:

https://doi.org/10.1080/13527259408722129

Anne Bationo Tillon, Isabelle Marchal and Pascal Houlier. 2011. Mobile augmented reality in the museum: can a lace-like technology take you closer to works of art? IEEE International Symposium on Mixed and Augmented Reality - Arts, Media, and Humanities, Basel, 2011, pp. 4147, DOI: http://dx.doi.org/10.1109/ISMAR-AMH.2011.6093655

Rafal Wojciechowski, Krzysztof Walczak, Martin White and Wojciech Cellary. 2004. Building virtual and augmented reality museum exhibitions. Proceedings of the ninth international conference on 3D Web technology (Web3D '04), pp. 135-144, DOI: http://doi.acm.org/10.1145/985040.985060

Niels Wouters, John Downs, Mitchell Harrop, Travis Cox, Eduardo Oliveira, Sarah Webber, Frank Vetere and Andrew Vande Moere. 2016. Uncovering the honeypot effect: how audiences engage with public interactive systems. Proceedings of the 2016 ACM Conference on Designing Interactive Systems (DIS '16), pp. 5-16, DOI: http://dx.doi.org/10.1145/2901790.2901796 
Architectural contextualization of Museum Artifacts Using AR $\quad 2: 67$

Rabia M. Yilmaz. 2016. Educational magic toys developed with augmented reality technology for early childhood education. Computers in Human Behavior, 54 (2016), pp. 240-248, DOI: http://dx.doi.org/10.1016/j.chb.2015.07.040

Received March 2018; revised June 2018; accepted July 2018.

Studies in Digital Heritage, Vol. 2, No. 1, Publication date: September 2018 